\title{
artículos
}

\section{La galería española de Luis Felipe de Orleáns y sus vinculaciones con el patrimonio pictórico de Córdoba}

\author{
José Antonio Vigara Zafra
}

Universidad Nacional de Educación a Distancia (UNED)

\section{RESUMEN}

Este trabajo pretende un análisis de la misión ejecutada por el Barón Taylor en España, gracias a la cual se formó la Galería Española de Luis Felipe de Orleáns en 1838. Para ello se estudia la red de colaboradores que formó Taylor en Andalucía, que le permitieron obtener gran cantidad de obras pictóricas a muy bajo coste. Centrando esta investigación en el caso del patrimonio pictórico de Córdoba. Con ello se esperan extraer consecuencias relativas al análisis de la dispersión y el robo de obras de arte en España durante el siglo XIX.

PALABRAS CLAVE: Barón Taylor/ Coleccionismo/ Córdoba/ Diego Monroy/ Luis Felipe de Orleáns/ Patrimonio Pictórico/ siglo XIX.

\section{rial heritage of Córdoba}

Louis Philippe D'Orleans' spanish gallery and his connections with the picto-

ABSTRACT

This work aims an analysis of the mission executed by Baron Taylor in Spain, which supported the formation of Louis Philippe d'Orleáns'Spanish Gallery of 1838. In order to do so, the network of assistants that Taylor trained in Andalusia is studied. It allowed him to obtain a great number of paintings in a very low cost. The article is focused in the pictorial heritage of Córdoba. This case study intends to provide readings about the dispersion and the theft of works of art in Spain during the 19th Century.

KEY WORDS: Baron Taylor/ Art Collection/ Córdoba/ Diego Monroy/ Louis Philippe d'Orleans/ Pictorial Heritage/ XIX century.

En 1838, Frank Hall Standish, viajero y coleccionista inglés, se quejaba de lo poco que el gobierno británico invertía en materia artística. En realidad, iba más allá, y se lamentaba de que su país no hubiera imitado la iniciativa llevada a cabo por el rey francés Luis Felipe de Orleáns, comprando obras de arte de la Península Ibérica:

"Very many pictures, of more or less merit, have been purchased by Baron Taylor in Andalusia; and with the additions from Madrid, Valencia, and London, the Spanish gallery in France will certainly be a very fine one. Why do we not follow the example of our neighbours? One of the many millions wasted in extraordinary expenditure by the late royal family and the Tory ministry would have furnished us forth most nobly with

* VIGARA ZAFRA, José Antonio: "La galería española de Luis Felipe de Orleáns y sus vinculaciones con el patrimonio pictórico de Córdoba", en Boletín de Arte n 32-33, Departamento de Historia del Arte, Universidad de Málaga, 2011-2012, págs. 649-664. Fecha de recepción: Junio de 2011. 
pictures of every school; - and what have we now? An eleemosynary collection, which doubtless contains some good paintings, but is anything but important in proportion to the dignity of the nation:-and a debt which would have ruined any other save our own. Why have we not also the finest collection of coins in the world? If we look to the British Museum, the legacy of Mr. Payne Knight is perhaps worth as much as its trustees have ever collected. The national propensities of the British, a taste for field sports and the pleasures of the table, and rivalry in pomp of reception and splendour of establishment, are indeed at length giving way, although too slowly, to an amelioration in taste, and a growing regard for the fine arts is doubtless visible. Would that it were in my power to hasten the day when we might vie with other nations in elegance and politeness, as we have long done in arms and opulence..."1.

La singularidad del citado testimonio de Standish², amigo y compañero de viaje del barón Taylor por España, radica en la importancia que desde el extranjero comenzó a darse a la pintura española ${ }^{3}$. Pero, sobre todo, nos informaba en fechas coetáneas de la que en palabras de Francisco Calvo Serraller "fue la más grande operación organizada en pos de obtener una colección de pinturas españolas" en el siglo XIX4 . Se refería a la misión que el monarca francés, Luis Felipe de Orleáns, encargó al barón Taylor con el objeto de adquirir obras capitales de la pintura española, para su posterior exposición en el Museo del Louvre ${ }^{5}$.

En efecto, el 7 de enero de 1838 se inauguró en París la Galería Española del Museo del Louvre en las salas de la Colonnade. Ciertamente, no resulta extraño el éxito de la misma, si tenemos en cuenta que contaba con más de cuatrocientos cincuenta cuadros de los más diversos pintores de la escuela española y de la calidad de muchos de estos lienzos, cuyas autorías fueron atribuidas a pintores tan destacables como El Greco, Velázquez, Murillo, Alonso Cano, Ribera, Valdés Leal o Goya, por citar sólo algunos de los integrantes de esta amplia nómina de autores que englobaron dicha galería.

1 STANDISH, F. H., The shores of the Mediterranean. London, R. Lumley, 1838, págs. 228-229.

2 La admiración de Standish hacia Luis Felipe de Orleáns fue tal, que tras varios intentos por vender su colección al gobierno británico, decidió legarla al monarca francés en 1841, engrosando la colección de este último con 585 obras entre cuadros, dibujos y grabados. Vid. STANDISH, F. H., Catalogue des tableaux, dessins, et gravures de la collection Standish, légués au Roi par M. F. H. Standish. Paris, L'imprimerie de Crapelet, 1842.

3 Este tema ha sido tratado tanto por historiadores españoles como foráneos, coincidiendo la mayoría en que la diseminación de pintura española por distintos países europeos durante la primera mitad del siglo XIX, generó un gusto y un aprecio singular por la misma. Vid. CABANIS, J., Le Musée espagnol de Louis Philippe. Goya. Paris, Éditions Gallimard, 1985; HEMPEL LIPSCHUTZ, I., La pintura española y los románticos franceses. Madrid, Taurus, 1988; GARCÍA FELGUERA, M. S., Viajeros, eruditos y artistas: los europeos ante la pintura española del siglo de oro. Madrid, Alianza Editorial, 1991; AA. VV., Manet/Velázquez: the French taste for Spanish painting. New York, Metropolitan Museum of Art, 2003.

4 CALVO SERRALLER, F., La imagen romántica de España. Arte y arquitectura del siglo XIX. Madrid, Alianza Editorial, 1995, pág. 88.

5 GRANGER, C., L'Empereur et les Arts. La liste civile de Napoléon III. París, École des Chartes, 2005, págs. 24-35. 
Sin embargo, los incidentes revolucionarios de 1848 que apartaron del poder al último monarca francés y dieron comienzo a la II República, también cercenaron la vida de la citada galería, al menos en suelo galo. Luis Felipe de Orleáns, una vez depuesto de su cargo como rey de Francia, se exilió a Londres, y por supuesto, hasta allí trasladó su rica colección de pintura. Finalmente, tras la muerte de éste en agosto de 1850, su colección fue vendida por sus hijos en Londres en subasta pública. Dicha subasta fue organizada por los señores "Christie \& Manson" ${ }^{\text {, }}$ en el número 8 de King Street en mayo de 1853, pasando la mayoría de estas obras a manos de coleccionistas británicos ${ }^{7}$.

Muchos han sido los estudios que desde entonces se han dedicado a analizar la citada galería en sus más diversos aspectos ${ }^{8}$. En ese sentido, algunos han incidido en la fortuna crítica de dicha colección y en la importancia que tuvo para la transmisión del gusto por la pintura española en Europa. Igualmente, se han centrado en localizar el destino de muchas de estos lienzos subastados en $1853^{9}$. Y también, contamos con investigaciones parciales de los personajes que intervinieron en esta misión, centradas principalmente en la figura del barón Taylor ${ }^{10}$, aunque no hemos de obviar las dedicadas a los pintores Adrien Dauzats ${ }^{11}$ y Pharamond Blanchard ${ }^{12}$, que secundaron a Taylor al frente de esta misión.

6 Catalogue of a Portion of the Superb Effects, the property of his Majesty the late King Louis Philippe, which decorated the royal palace, the Chateau d'Eu; which will be sold by auction, by Messrs. Christie and Manson. May 5, 1853. London, W. Clowes \& Sons, 1853; Catalogue of the Pictures forming the Celebrated Standish Collection, bequeathed to his Majesty, the late King Louis Philippe, by Frank Hall Standish, Esq.: which will be sold by auction, by Messrs. Christie and Manson. May 27 \& 28, 1853. London, W. Clowes \& Sons, 1853.

7 Aunque muchas de las obras pasaron a manos de coleccionistas ingleses, su hijo Antonio, Duque de Montpensier, se quedó con cuadros muy representativos. Vid. RODRÍGUEZ REBOLLO, Ángel, Las colecciones de pintura de los Duques de Montpensier en Sevilla (1866-1892). Madrid, Fundación Universitaria Española, 2005, págs. 29-87.

8 Este tema tuvo muchísima repercusión, incluso en las mismas fechas en las que fue creada la galería, así fueron múltiples los críticos de arte que dejaron su opinión sobre este relevante acontecimiento. Vid. JUBINAL, A., Notice sur M. le baron Taylor et sur les tableaux espagnols achetés par lui d'après les ordres du roi. Paris, É. Pannier, 1837; BLAZE, H., "La Galerie espagnole au Louvre", Revue des Deux-Mondes, 15 mai 1837 págs. 532-543; DE MATOUGUES, B., "Le Musée Espagnol”, Le Lithographe, 1838, págs. 65-79 y 105-118; CIRCOURT, A., "La Galerie espagnole", France et Europe, 25 mai et 25 juin 1838; DECAMPS, A., "Le Musée espagnol", Le National, 15 février 1838.

9 El estudio de Jeannine Baticle y Cristina Marinas es fundamental para conocer la autoría exacta de muchos de los pintores que integraron dicha galería. Vid. BATICLE, J., y MARINAS, C., La Galerie Espagnole de LouisPhilippe au Louvre. 1838-1848. Paris, Editions de la Réunion des Musées Nationaux, 1981.

10 Los estudios dedicados a analizar las diferentes vertientes de la actividad profesional del barón Taylor han sido muy variados, aunque no todos han incidido en el plano que nos ocupa, el de su vinculación con el patrimonio. En ese sentido, los estudios más acertados sobre este tema los ofrecen Juan Plazaola, Jean Pierre Bernés, Éliane Maingot y Mohamed Chouaa, Vid. MAINGOT, E., Le baron Taylor. Paris, Editions de Boccard, 1963; BERNÉS, J. P., Un Voyageur français en Espagne dans la première moitié du XIXe siècle: le Baron Taylor. Tesis Doctoral Inédita, Universidad de París X Nanterre, 1973; PLAZAOLAARTOLA, J., Le baron Taylor. Portrait d'un homme d'avenir. Paris, Fondation Taylor, 1989, págs. 121-143; CHOUAA, M., L'Espagne et la Maroc dans Le voyage pittoresque du Baron Taylor. Tesis Doctoral, Paris III, 1993.

11 FOUCART, B., Adrien Dauzats et Les Voyages pittoresques et romantiques dans l'ancienne France de baron Taylor. Paris, 1990.

12 El estudio que Paul Guinard dedicó a ambos pintores, es a día de hoy, y a pesar de los años que han transcurrido desde su publicación, una de las investigaciones más concienzudas y mejor documentadas que se han realizado sobre la implicación de Dauzats y Blanchard en la misión del barón Taylor. Destacando por el nutrido aporte de fuentes documentales, aunque carece de un análisis crítico de lo que realmente fue esta misión artística por tierras españolas. Vid. GUINARD, P., Dauzats et Blanchard, peintres de l'Espagne romantique. París, Presses Universitaires de France, 1967. 
En cambio, como ha señalado recientemente Alisa Luxenberg ${ }^{13}$, aún no se han analizado en profundidad todas las implicaciones del proceso de compra fraudulenta de obras de arte que llevaron a cabo Taylor, Dauzats y Blanchard; contando éstos con la inestimable ayuda de muchos 'amigos'14 y testaferros españoles que les allanaron el camino para la consecución de innumerables piezas.

Así, el barón Taylor, gracias a los importantes contactos que tuvo dentro de la intelectualidad española, urdió toda una trama dedicada a la compra de pinturas, ya fuera de manera legal o ilegal ${ }^{15}$. De hecho, fueron muchos los que vieron en esta operación un gran negocio, y no pensaron en ningún momento el daño que se le hacía al patrimonio español.

En ese sentido, uno de sus colaboradores fue el pintor cordobés Diego José Monroy y Aguilera ${ }^{16}$. Este artista, supo aprovechar como tantos otros su condición de integrante de las Comisiones Provinciales de Monumentos. Gracias a este cargo, accedió a cientos de cuadros recogidos de los conventos desamortizados de la provincia de Córdoba, y extrajo algunos sin levantar las más mínimas sospechas. No obstante, atendiendo a la valiosa documentación localizada en los Archivos Nacionales de París, hemos podido determinar hasta donde llegó el grado de implicación de Monroy dentro de esta misión, e incluso conocer la procedencia y el paradero de las obras que expolió.

LA Gestación de LA Misión ‘SeCRETA' del baRón TAYLOR.

Con el pretexto de completar y realizar los dibujos correspondientes a su "Voyage pittoresque en Espagne”, el barón Taylor acudió a España junto con los pintores Dauzats y Blanchard, llegando a Cádiz el 15 de diciembre de $1835^{17}$. En efecto, esta noticia

13 La reciente investigación de Alisa Luxenberg, establece conexiones y paralelismos entre la Galería Española de Luis Felipe y el Museo Nacional de Madrid, creados en fechas similares, vid. LUXENBERG, A., The Galerie Espagnole and the Museo Nacional 1835-1853. Saving Spanish Art, or the Politics of Patrimony. Hampshire, Ashgate Publishing, 2008, págs. 1-11. Este estudio ya fue esbozado en un artículo anterior de la misma autora, donde se dedicó a explicar la conformación de la Galería de Luis Felipe, vid. LUXENBERG, A., "La Galería Española del Louvre (1838-1848): ética de adquisición, política de patrimonio", Goya, 321, 2007, págs. 353-364.

14 El barón Taylor supo relacionarse con las altas esferas de la cultura española del momento. De hecho, fue amigo de las personalidades más influyentes del momento en materia de patrimonio artístico. Vid. MADRAZO, F., Epistolario I. Madrid, Museo del Prado, 1994.

15 Con respecto a la compra ilícita de obras de arte por parte de Taylor, hemos de advertir que dentro de presupuesto que le asignó el rey Luis Felipe de Orleáns para la consecución de la misión, se estableció una partida de dinero, cuya razón de ser fue la de financiar regalos a diferentes conventos, como un medio para lograr seducir a los religiosos, adquiriendo así las piezas pretendidas. Vid. Archives Nationales de París (en adelante A. N. P.), $0^{4}$ 1725. 3 Aôut 1838. Etat récapitulatif des déspenses occasionnées par la Mission qu'a remplie $\mathrm{M}^{\mathrm{r}}$ le $\mathrm{B}^{\text {on. }}$ Taylor, pendant les années 1835,1836 et 1837 pour acquisistion de tableaux de l'Ecole Espagnole et d'objets d'art.

16 VIGARA ZAFRA, J. A., La figura del artista en Andalucía en el tránsito de la modernidad a la contemporaneidad: el pintor cordobés Diego Monroy y Aguilera. Trabajo de investigación inédito, Universidad Nacional de Educación a Distancia (UNED), 2009.

17 TAYLOR, I. J., Voyage pittoresque en Espagne, en Portugal et sur la côte d'Afrique, de Tanger a Tétuan. Paris, Librairie de Gide Fils, 1826; PARDO, A., La visión del arte español en los viajeros franceses del siglo XIX. 
quedó reflejada en un artículo publicado en la revista "El Artista", que dirigían Federico de Madrazo y Eugenio de Ochoa, a la sazón amigos de Taylor y Dauzats. En el citado artículo, que muestra de manera ejemplar hasta donde llegaba la influencia del barón Taylor y la fundamental ayuda que le concedieron los Madrazo, se hizo saber al gobierno la llegada de éstos, pidiéndole encarecidamente que les dotasen de la ayuda necesaria para facilitar la labor literaria y artística que el barón Taylor y Dauzats estaban perfilando:

"La obra que se propone publicar en Paris el Sr. Baron Taylor, tendrá por título Viage pintoresco á España, y con sus numerosas láminas y con los testos que acompañarán á cada una de ellas, estamos seguros de que será la que mas contribuya á hacer conocer en Europa el verdadero carácter de las bellas artes españolas. El Baron Taylor no es un simple especulador político, un mero observador geógrafo ó un entusiasta novelista como la mayor parte de los autores que hasta ahora han escrito acerca de las cosas de España; el Baron Taylor es todo aquello y es además artista y poeta. Esto es decir que reune todos los elementos necesarios para llevar á cabo dignamente el vasto plan de su obra; ademas, y sea dicho de paso, tenemos entendido que no ha perdonado gasto alguno para que sea enteramente digna de su autor y del ilustrado siglo XIX. Los Sres. Taylor y Dauzats pasarán una breve temporada en Madrid, donde esperamos que el gobierno les facilite todos los medios de reunir el mayor número posible de datos para su importante obra, y continuarán luego su viaje á las provincias litorales del mediterráneo. Al sentir y manifestar públicamente nuestros vivos deseos de que el mas brillante éxito corone los trabajos de estos ilustres estrangeros, lo hacemos no solo por un sentimiento de simpatía como artistas, mas tambien de gratitud como españoles ${ }^{18 "}$.

Sin duda, con este artículo pretendieron allanar el trabajo de los señores Taylor y Dauzats. Pero, también contrarrestar algunas opiniones que denunciaban la presencia de extranjeros en la Península lbérica, cuyo único objetivo era el de comprar obras de arte, a consecuencia del clima tan propicio que se fraguó en España con la desamortización de Mendizábal y con la Primera Guerra Carlista ${ }^{19}$.

Valladolid, Secretariado de Publicaciones de la Universidad de Valladolid, 1989, págs. 137-178.

18 "El Baron Taylor.- Mr. Dauzats", El Artista, T. III, 1836, pág. 48.

19 Ya en 1835, el hispanista Louis Viardot, advertía que el momento para la adquisición de obras de arte era el más propicio a consecuencia del pésimo estado económico que asolaba al erario español, vid. VIARDOT, L., Etudes sur l'histoire de institutions, de la littérature et des beaux arts en Espagne. Paris, Paulin Éditeur, 1835, pág. 438:

"Je voudrais ensuite qu'il fût chargé de faire quelques achats de tableaux. Le moment est favorable, et l'occasion bonne à saisir. Toutes les grandes familles d'Espagne sont ruinées; il ne leur reste guère, de leur vieille splendeur, que des troupes de valets dont la livrée tombe en guenilles, et des galeries de tableaux qui seront bientôt exposés au grand air, faute de toit pour les couvrir. D'une autre part, les couvens sont menacés; on ne peut tarder de rendre leurs biens de main-morte à l'agriculture, leurs vastesbâtimens à l'industrie, leurs reclus à la population; alors toute la défroque sera mise à l'encan. En vérité, avec les nobles et les moines, il y a, comme on dit, de bonnes affaires à faire, et l'on serait bien maladroit si le bénéfice des tableaux revendus en France ne payait toutes les dépenses du voyage; y compris même celles du grand ouvrage qui, réunissant les travaux de ses membres, perpétuerait, dans un livre monumental, le souvenir de l'expédition..." 
Es curioso advertir, como uno de los personajes españoles más cercanos a Taylor, el escritor Mariano José de Larra ${ }^{20}$, fue el primero en denunciar al erudito francés en un artículo anónimo que apareció en la "Revista Mensajero" en agosto de 1835, donde sin citar nombres concretos, dejaba entrever la misión del barón, y llamaba la atención sobre las tropelías que éste y sus secuaces podrían ejercer en suelo hispano si el gobierno no tomaba las medidas necesarias para evitarlo ${ }^{21}$.

Aunque desde un comienzo intentaron llevar a cabo de forma secreta la misión que les encomendó Luis Felipe de Orleáns ${ }^{22}$. Ésta era conocida por un nutrido colectivo de la intelectualidad y de la aristocracia española, que no dudaron en ayudar, halagar y hacer negocio con el barón Taylor ${ }^{23}$.

Así, pese a las advertencias de las intenciones del barón Taylor, éste logró llevar a cabo su misión entre el 27 de octubre de 1835 y el 27 de abril de 1837. En ese tiempo, y sin apenas contratiempos, consiguió adquirir y trasladar a París cuatrocientos cincuenta y cuatro cuadros ${ }^{24}$. Tan magna operación, como ya hemos comentado con anterioridad, necesitó de un nutrido grupo de colaboradores que actuaron sobre todo en Andalucía, de donde procedía el grueso de la incautación.

20 RUMEAU, A., "Mariano José de Larra et le baron Taylor: le Voyage pittoresque en Espagne", Revue de Littérature Comparée, 3, juillet-septembre 1936, págs. 477-493.

21 Este perspicaz artículo de Mariano José de Larra se publicó bajo el seudónimo de Fígaro, cuando residía en París, vid. DE LARRA, M. J., "Conventos españoles. Tesoros artísticos encerrados en ellos", Revista Mensajero, 156, 3 de agosto de 1835:

"... ¿Qué no ha perdido la Francia por no haber pensado al principio de su Revolución en un ramo tan importante? ¿Qué de quejas no alzan hoy al cielo, estériles ya por desgracia y muy tardías? No sabemos hasta qué punto será apreciado nuestro patriotismo - si es que llega siquiera a los oídos de alguien, si es que encuentra eso -. Pero sí nos apresuramos a hacer presente al Gobierno, para excusarnos de visionarios, que esos mismos extranjeros que creen conocer nuestra posición, se ocupan en el día de salvar esos tesoros artísticos de nuestra España; pero en salvarlos para ellos. Sabemos positivamente que un establecimiento literario, en París, trata de enviar a nuestro suelo, con anuencia y protección de su Gobierno, comisionados encargados de diseñar o de comprar a cualquier costa cuanto puedan encontrar en punto a cuadros y manuscritos, etc., etc. ¿Podremos fiarnos en que estos objetos no les serán vendidos? ¿Podremos suponer a sus poseedores tan poco perspicaces que no vean al ojo su agonía? ¿Deberemos ponernos en manos de su delicadeza? Repetimos que lo sabemos positivamente, y lo podemos decir con tanta más independencia cuanto que hemos arrancado casualmente el secreto, y que no nos ha sido confiado.

Hagamos, pues, nosotros lo que los extranjeros piensan hacer, y apresurémonos; porque acaso el día de las venganzas, o el del triunfo completo de la buena causa, no esté lejos; y el día de enmendar una imprevisión, si la cometiésemos, no volvería a presentarse jamás..."

22 PLAZAOLAARTOLA, J., Op. Cit., pág. 124

23 Ibídem, pág. 132:

"...Le 9 décembre Dauzats embrassait Taylor à Séville. A partir de cette date, on peut suivre au jour le jour, dans le carnets de Dauzats, leur pérégrination en Andalousie: Séville, Cadix, Puerto de Santa María, Sanlúcar. Ils sont invités dans les familles les plus distinguées. Ils visitent à Séville le musée privé de M. Bravo, la collection de Jualian Williams, une riche commerçant anglais qui possédait très beaux Murillo, et celle de Don Manuel López Cepero, le célèbre chanoine de la cathédrale, passionné d'art et de politique. Ils resserrèrent leurs liens d'amitié avec Fernán Caballero, l'illustre écrivain, devenue par son nouveau mariage, marquise del ArcoHermoso. Cependant, ils n'oubliaient pas leur objectif principal: dessiner et... acheter".

24 El grueso de la misión del barón Taylor salió tal y como éste la había diseñado, aunque sí tuvieron diversos problemas originados por la guerra carlista que asolaba zonas cercanas a Andalucía. Vid. GUINARD, P., Op. Cit., págs. 202-203. 
El círculo de testaferros andaluces del barón Taylor: Diego Monroy y Aguilera, el “ChAMARILERo” cordobÉs.

Sin lugar a dudas, fue Andalucía la zona más afectada por el expolio practicado por el barón Taylor. Ya advertía George Borrow al encontrarse con Taylor en Sevilla, que éste se centró principalmente en comprar cuadros en las distintas provincias andaluzas, por ser éstas "las tierras de las artes" 25 , y contener el mayor número de obras de la denominada escuela andaluza, que a la postre fue la que más interesó a los franceses ${ }^{26}$.

En Andalucía, tejieron una red perfectamente articulada a partir de marchantes de obras de arte y testaferros que trabajaron directamente para el barón Taylor, supervisados y coordinados en gran medida por Dauzats ${ }^{27}$.

Los integrantes de esta red, fueron en su mayoría personalidades pertenecientes a las élites de la sociedad civil y religiosa, tal es el caso por ejemplo de Manuel López Cepero. De igual manera, tuvieron un papel muy destacado comerciantes y diplomáticos franceses e ingleses como Julián Williams, Alphonse de Rayneval, Antoine de Dominé o Louis Buisson, que residían principalmente en Sevilla y Cádiz, y que gracias al menor control que el Estado ejercía sobre ellos y a la inmunidad diplomática de algunos de éstos, desarrollaron sin problemas sus actividades de compra de obras de arte ${ }^{28}$. Por último, y no menos importante para el éxito de esta misión, disfrutó de la ayuda de distintos profesionales vinculados al mundo de las artes, en su mayoría pintores, como por ejemplo José Bueno, José Antonio de Mesa, José María Escacena y el propio Diego Monroy. Éstos le vendieron a Taylor obras procedentes de sus colecciones particulares, y además actuaron

25 BORROW, G. H., The bible in Spain; or, The journeys, adventures, and imprisonments of an Englishman, in an attempt to circulate the scriptures in the peninsula. London, Jonh Murray, 1843, págs. 319-320:

“...as I was passing by the portal of a large gloomy house near the gate of Xeres, two individuals dressed in zamarras emerged from the archway, and were about to cross my path, when one, looking in my face, suddenly started back exclaiming in the purest and most melodious French: What do I see ? If my eyes do not deceive me-it is himself. Yes, the very same as I saw him first at Bayonne ; then long subsequently beneath the brick wall at Novogorod; then beside the Bosphorus; and last at-at-Oh, my respectable and cherished friend, where was it that I had last the felicity of seeing your well remembered and most remarkable physiognomy? Myself. — It was in the south of Ireland, if I mistake not. Was it not there that I introduced you to the sorcerer who tamed the savage horses by a single whisper into their ear? But tell me what brings you to Spain and Andalusia, the last place where I should have expected to find you?

Baron Taylor. - And wherefore, my most respectable B...? Is not Spain the land of the arts; and is not Andalusia of all Spain that portion which has produced the noblest monuments of artistic excellence and inspiration. Surely you know enough of me to be aware that the arts are my passion; that I am incapable of imagining a more exalted enjoyment than to gaze in adoration on a noble picture. O come with me! For you too have a soul capable of appreciating what is lovely and exalted; a soul delicate and sensitive. Come with me and I will show you a Murillo, such as..."

26 CALVO SERRALLER, F., Op. Cit., págs. 82-84.

27 Los viajes de Adrién Dauzats por Andalucía están perfectamente documentados en el trabajo de Paul Guinard, y nos permiten ver la importancia que tuvo el núcleo andaluz para el desarrollo de la misión dirigida por el barón Taylor. Vid. GUINARD, P., Op. Cit., págs. 426-430.

28 Sobre el papel de los diplomáticos británicos en la compra de obras de arte españolas. Vid. GLENDINNING, N., "Nineteenth-Century British Envoys in Spain and the Taste for Spanish Art in England", The Burlington Magazine, 131, febrero 1989, págs. 117-126. 
como intermediarios para la compra de cuadros, e incluso restauraron muchas de estas pinturas antes de ser enviadas a París.

Las dos principales ciudades donde se realizaron el grueso de las compras fueron Sevilla y Cádiz, y en menor medida, Granada y Córdoba, no teniendo constancia de que hubieran actuado en alguna otra capital andaluza.

Por los datos extraídos en los Archivos Nacionales de París, estamos en condiciones de afirmar que la mayoría de los integrantes de la red comercial urdida por el barón Taylor, mantuvieron relaciones de amistad y estuvieron en contacto entre sí continuamente. Muestra de ello son los encuentros continuos que tuvo el barón Taylor con Manuel López Cepero, o los de Louis Buisson con Aniceto Bravo ${ }^{29}$.

Desde el inicio de las operaciones, fueron muy escrupulosos a la hora de emitir recibos por cada una de las compras que se llevaron a cabo, ya que en una hipotética reclamación de alguna de las pinturas, el recibo correspondiente demostraría la legitimidad de la adquisición. E incluso, la mayoría de estos recibos iban traducidos al francés, para una mejor comprensión por parte de las autoridades judiciales. Además, el barón Taylor remitió un listado completo con todos los gastos que ocasionó la nombrada misión, donde pormenorizaba cada uno de los pagos que realizó, indicando la persona, la fecha y el importe que se le remitía a cada uno de ellos. De esta manera, sabemos que aunque el total de la misión costó $1.283 .737,77$ francos, lo destinado a la compra de obras de arte fue exactamente 1.159.658,40 francos ${ }^{30}$.

El gran núcleo de todas estas actividades fue Sevilla. En dicha ciudad, se localizaron las mejores y más completas colecciones de pinturas en manos de un reducido número de coleccionistas, pero además fue allí donde el barón Taylor reclutó un buen número de los contactos y testaferros que trabajaron para él. Por lo tanto, fue Sevilla el punto principal en torno al cual se articularon todas las operaciones de esta misión en tierras andaluzas. El grueso de sus más activos colaboradores se halló en dicha ciudad, pero las actuaciones de los mismos se extendieron desde Córdoba a Cádiz, destacando los siguientes:

Manuel López Cepero ${ }^{31}$, canónigo de la Catedral, coleccionista, primer director del Museo Provincial de Bellas Artes de Sevilla y amigo del barón Taylor. Y sin lugar a dudas, uno de los que mejores obras le vendió. Pero además, utilizó sus influyentes contactos para conseguir diversas pinturas para la galería de Luis Felipe de Orleáns, hecho que podemos constatar gracias a un recibo de 30 de enero de 1837 donde expresa como ha vendido algunos cuadros de su colección al barón Taylor y ha

29 MERCHÁN CANTISÁN, R., El deán López-Cepero y su colección pictórica. Sevilla, Diputación Provincial de Sevilla, 1979, págs. 39-42.

30 A. N. P., $0^{4} 1275$, Prix de l'acquisition faite par Mr. Le Bon. Taylor, de tableaux de l'Ecole Espagnole et de divers objets d'art; fruis de voyage, dépenses diverses. 3 agosto 1838.

31 Le vendió obras de su colección privada por el valor de 66.675 francos. 
mediado para la compra de otros entre varios de sus amigos ${ }^{32}$, o su influencia para la venta del "Ecce-Homo" de Murillo procedente de la Catedral de Sevilla ${ }^{33}$.

José María Escacena y Daza ${ }^{34}$, fue pintor, restaurador, coleccionista ${ }^{35}$ e incluso guía turístico ${ }^{36}$. Su relación con el barón Taylor y con Julián Williams ${ }^{37}$ fue crucial para la obtención de muchas de las pinturas que posteriormente se enviaron a París. "Josef Escazena", como firmaba sus recibos, ejerció de intermediario en la compra de pinturas para Taylor, tanto en Sevilla como en Cádiz:

"He vendido al Señor Baron de taylor los tres cuadros siguientes y cuarenta y siete estampas todo lo que he entregado á Dn. José Escacena de quien he recivido cinco mil y quinientos reales de vellon en que fueron ajustados:1. Cristo con la Cruz á Cuestas/1. Sacrificio de Abrahám/1. País de Verghem/47. Estampas de grabado español. Cadiz Mayo 16 de 1836, Manuel Saenz de Tejada ${ }^{38 " . ~}$

Por estos trabajos recibió un $8 \%$ de la tasación de cada una de las obras ${ }^{39}$. De igual manera, también le vendió varias obras de su propia colección por un valor de 44.208 reales de vellón, según consta en recibo de 28 de diciembre de $1836^{40}$.

Julián B. Williams, vicecónsul británico en Sevilla, experto coleccionista de pintura, y según Richard Ford, el hombre al que tenía que visitar todo inglés que quisiera conocer en profundidad la ciudad de Sevilla y la pintura de la escuela andaluza ${ }^{41}$. Su

32 A. N. P. $0^{4}$ 1275, Etat des dépenses relatives à la mission de M. Le Baron Taylor en Espagne pendant les années 1835, 1836 et 1837. Achât de tableaux espagnole. 30 de enero de 1837:

"He recibido del Sr. Baron Taylor treinta mil pesetas por el valor de algunos cuadros de mi propiedad que le he vendido y de otros que por mi mediacion ha comprado á varios de mis amigos.

Sevilla y Enero 30 de 1837. Manuel Lopez Cepero".

33 GAYA NUÑO, J. A., La pintura española fuera de España. Historia y catálogo. Madrid, Espasa-Calpe, 1958, pág. 22.

34 VALDIVIESO, E., Pintura sevillana del siglo XIX. Sevilla, Editorial Sever-Cuesta, 1981, pág. 33-34.

35 CÓMEZ RAMOS, R., "Coleccionistas de pintura en Sevilla en 1842", Laboratorio de Arte, 5, 1993, pág. 162-163.

36 DRUMMOND HAY, J. H., Western Barbary: Its wild tribes and savage animals. London, John Murray, 1844, pág. 5.

37 HOWARTH, D., The invention of Spain: cultural relations between Britain and Spain, 1770-1870. Manchester, Manchester University Press, 2007, pág.172.

38 Constan un total de tres recibos donde actúa de intermediario en la compra de varias pinturas a favor del barón Taylor. Vid. A. N. P., $0^{4} 1275$, Etat des dépenses relatives à la mission de M. Le Baron Taylor en Espagne pendant les années 1835,1836 et 1837 . Achât de tableaux espagnole.

39 En los Archivos Nacionales de París, hemos constatado dos recibos donde se muestra su labor como intermediario en la compra de pintura para el barón Taylor, y los porcentajes que recibió por cada una de estas ventas. Vid. A. N. P., $0^{4}$ 1725. Acquisition de tableaux espagnols. Compte de $\mathrm{M}^{r}$. Taylor. Cadeaux à divers:

"He recivido de los Sres. Baron Taylor y el Sr Dn Alfonso de Rayneval la cantidad de dos mil ochocientos doce reales de vellon por compra echa de barias pinturas al oleo a valor de treinta y seis mil quatrocientos reales de vellon a razon de ocho por cien según costumbre. Cadiz 14 de Mayo 1836. Josef Escazena.

Recibi del Sr. Baron Taylor seiscientos reales vellon por mi comision de la compra de pinturas de importe siete mil quinientos reales de vellon para que conste doy la presente. Cadiz 16 de mayo 1836. Josef Escazena".

40 A. N. P., $0^{4}$ 1275, Etat des dépenses relatives à la mission de M. Le Baron Taylor en Espagne pendant les années 1835, 1836 et 1837. Achât de tableaux espagnole, 28 diciembre 1836:

"Recivi del Sr. Baron Taylor la catida de quarenta y quatro mil dociento y ocho en reales de vellon por la benta de barios quadro y para que coste lo firmo en Sevilla a 28 de diciembre de 1836. Josef Escacena".

41 FORD, R., Manual para viajeros por Andalucía y lectores en casa que describe el país y sus ciudades, los 
colección de pintura fue muy valorada por sus coetáneos, aunque despertó los recelos de muchos de ellos, que no vieron con buenos ojos las continuas ventas que éste realizaba a extranjeros. En ese sentido, Vicente Álvarez Miranda recoge un texto de un cronista de la época, pidiéndole que cesara la venta de pinturas de su colección:

"Al terminar la descripción de esta galería, el escritor antes mencionado, sintiendo vivamente que el Sr. Williams se haya deshecho de muchas obras, tanto de la escuela sevillana, como de las estanjeras, que eran el mas precioso ornamento de su coleccion, añade: como amantes de Sevilla é interesados en sus glorias, nos atrevemos á suplicarle que conserve las existentes, en lo cual veran los aficionados á las artes un servicio de no poca monta. Si el señor Williams fuese español, no hubiéramos titubeado en dirigirle un cargo, y cargo tal vez severo por enagenacion semejante; pero recordamos que pertenece á otra nacion y en este concepto solo nos toca rogarle que no saque de nuestro suelo joyas que en él ha recogido, y que en último resultado son esencialmente españolas ${ }^{42 "}$.

Pese a estas suplicas, el vicecónsul británico continuó realizando transacciones económicas con las pinturas de su colección, y al barón Taylor le vendió diversos lienzos por valor de 38.492 francos ${ }^{43}$. Pero su relación con Taylor fue más allá, y ejerció de marchante para éste, recogiendo y pagando obras en su nombre ${ }^{44}$.

Antoine de Dominé, negociante francés afincado en Sevilla, que junto con Louis Buisson, fueron los que más trabajaron como marchantes para el barón Taylor. Actuó en la ciudad de Sevilla entre 1836 y 1837, vendiéndole a Taylor obras de Zurbarán, Murillo o Herrera el Viejo, por un valor cercano a los 90.000 francos $^{45}$.

Louis Buisson, comerciante francés residenteen Sevilla, yqueejerció comomarchante y testaferro del barón Taylor y de Dauzats. Recibió un total de 8.000 reales de vellón por sus

nativos y sus costumbres; las antigüedades, religión, leyendas, bellas artes, literatura, deportes y gastronomía. Madrid, Ediciones Turner, 1988, pág. 242:

"Las colecciones más ricas son las de nuestro estimadísimo amigo don Julián, el vicecónsul inglés, quien, sin la menor duda, es el primer juez de Europa por lo que al arte español se refiere; su museo particular, sin embargo, es una sombra de otros tiempos, ya que las mejores piezas están en Inglaterra, Francia y Rusia, y especialmente, en París, debido a que el señor Standish, que compró muchas, legó su colección a Luis Felipe".

42 ÁLVAREZ MIRANDA, V., Glorias de Sevilla: En armas, letras, ciencias, artes, tradiciones, monumentos, edificios, caracteres, costumbres, estilos, fiestas y espectáculos. Sevilla, Carlos Santigosa editor, 1849, pág. 148.

43 Constan cuatro recibos de Julián Williams por venta de pinturas fechados en 9 y 10 de enero de 1836, 25 de abril de 1836 y 3 de septiembre de 1836 , vid. A. N. P., $0^{4} 1725$, Acquisition de tableaux espagnols. Compte de $\mathrm{M}^{r}$. Taylor. Etat des dépenses relatives à la mission de $\mathrm{M}$. le Baron Taylor, en Espagne, pendant les années 1835,1836 et 1837.

44 A. N. P., $0^{4}$ 1275, Etat des dépenses relatives à la mission de M. Le Baron Taylor en Espagne pendant les années 1835,1836 et 1837 . Achât de tableaux espagnole. 31 juillet 1837:

"He recibido de Mr. Dauzats por mano del Sr. D. Julian Williams la cantidad de sesenta mil reales de vellon. Sevilla 31 de julio 1837. Francisco Carassa".

45 De Antoine de Dominé contamos con varios recibos fechados en 6, 25, 26 y 28 de mayo de 1836, 2 de octubre de 1836, 29 de agosto de 1837, vid. A. N. P., $0^{4}$ 1275, Etat des dépenses relatives à la mission de M. Le Baron Taylor en Espagne pendant les années 1835, 1836 et 1837. Achât de tableaux espagnole. 
actuaciones como intermediario en la venta de obras de arte ${ }^{46}$. Sus intervenciones fueron cruciales ya que convenció a Aniceto Bravo ${ }^{47}$ para la venta de muchas de las mejores obras que atesoraba en su galería por un montante total de 486.000 reales de vellón ${ }^{48}$.

Si estos fueron los más señalados intermediarios del barón Taylor y los que efectuaron la mayoría de los negocios relacionados con la compra de pinturas en tierras andaluzas, en la ciudad de Córdoba, estas actividades fueron monopolizadas por Diego Monroy.

Monroy en calidad de pintor, coleccionista, miembro de la Comisión Artística y Científica y director del Museo Provincial de Bellas Artes, desarrolló un papel preponderante sobre el patrimonio cordobés proveniente de los conventos exclaustrados. Esto unido a sus relaciones con los miembros de la Real Academia de Bellas Artes de San Fernando, lo situaron a los ojos del barón Taylor como la principal personalidad con la que contar para llevar a cabo sus propósitos en la ciudad de Córdoba, y en efecto, así sucedió.

Entre el 19 de abril de 1836 y el 18 de julio de 1837, Monroy efectuó hasta seis operaciones documentadas de compra y venta de cuadros por valor de la nada despreciable cifra de casi 80.000 reales de vellón. La mayoría de las ocasiones, se trató de compras efectuadas de forma fraudulenta, o bien, le vendió piezas de su colección particular. En otras ocasiones actuó como intermediario para la compra de pintura a otros coleccionistas cordobeses. En ese sentido, y como hemos constatado en los recibos a su nombre, tuvo relaciones con personalidades relevantes de la red tejida por el barón Taylor como Alphonse de Rayneval (hijo del embajador francés en Madrid), Dauzats, y fundamentalmente,

46 A. N. P., $0^{4} 1725$, Acquisition de tableaux espagnols. Compte de Mr. Taylor. Cadeaux à divers:

"J'ai reçu monsieur Dauzats la somme de huit mille reaux vellon pour commission qu'il m'avonée sur l'achat des tableaux qu'il afait par moi intermediation. Seville Sep 1837. Luis Buisson".

47 En 1844, José Amador de los Ríos apuntaba que la galería de Aniceto Bravo contaba con 840 cuadros, constituyendo la más numerosa de la época en Sevilla, vid. AMADOR DE LOS RíOS, J., Sevilla pintoresca ó descripcion de sus mas célebres monumentos artisticos. Sevilla, Francisco Álvarez y C. a, 1844, págs. 409450.

48 Las compras efectuadas a Aniceto Bravo por mediación de Louis Buisson se constatan gracias a tres recibos fechados en 3 de octubre de 1836, 23 de noviembre de 1836 y 1 de septiembre de 1837 , vid. A. N. P., $0^{4} 1275$, Etat des dépenses relatives à la mission de M. Le Baron Taylor en Espagne pendant les années 1835, 1836 et 1837 . Achât de tableaux espagnole:

"He recivido del Sor. Dn. Luis Bouisson la cantidad de cincuenta mil reales de vellon importe de dos cuadros que representa el uno á santa Maria Magdalena calificada por todos los inteligentes por de Murillo, y el otro á San Pablo firmado por Jose Rivera conocido por El Españoleto. Sevilla 3 de octubre de 1836. Aniceto Bravo. He recibido del Sor. Dn. Luis Buisson la cantidad de treinta y seis mil reales de vellon por dos cuadros que el uno representa el Castillo de Emaus y el otro á Sn. Pedro ambos calificados por de Velazquez por los inteligentes, y por haberse estraviado el recibo doi el presente por duplicado. Sevilla 23 de Noviembre de 1836. Aniceto Bravo.

He recibido del Sor. Dn. Luis Bouisson la cantidad de cuatro ciento mil reales de vellon, importe de cinco cuadros del tenor siguiente; un Salbador y San Juan de Murillo según los inteligentes; una tabla del Sor. de Juan de Juanes; una Magdalena de Cano, según unos y de Cerezo según otros; la Alameda de Sevilla de Velázquez, y San Pedro de Herrera el Viejo.

Sevilla $1^{\text {er }}$ de Setiembre de 1837. Aniceto Bravo.

Je déclare que les tableaux ci dessus ont été achetés par ordre et pour compte de M. Dauzats de qui j'ai reçu leur moutant. L. Buisson". 
con Louis Buisson, uno de los más activos marchantes de Taylor, hecho que podemos validar gracias a una carta que dirigió a Monroy:

"Cordoba 23 de Diciembre de 1836

Sevilla, Sr. Dn. Luis Buisson

Muy Sr. Mio: he recivido su estimada del 20 del presente inclusa la letra de los tres mil reales, que hoy he cobrado, y entregado al dueño dela partida de aceite, que es el mismo de quien $\mathrm{V}$. me abla en la suya; y quedará encerrado hasta su aviso.

Los demas encargos hay esperanzas de poder recogerlos yo no lo descuido, y cuando haya alguna noticia de ellos lo avisare al momento, que es cuanto por ahora puedo hacer. Soy siempre su Affmo. servidor. Diego Monroy y Aguilera ${ }^{49 "}$.

Esta carta nos evidencia como fue Louis Buisson quien supervisó gran parte de las operaciones que se cerraron en la zona de Córdoba y Sevilla. De igual manera, nos indica que Diego Monroy estuvo en continua comunicación con él, teniéndolo al tanto de todas las operaciones que llevó a cabo. Y por otro lado, alude a 3.000 reales de vellón que cobró y que constan en la lista de pagos efectuados por el barón Taylor ${ }^{50}$, pero del que no hemos hallado su recibo correspondiente, por lo tanto desconocemos en calidad de que concepto se le expidió dicho recibo, aunque todos los indicios nos llevan a pensar que fue por la venta de cuadros.

En cuanto a las ventas de pinturas de Monroy a Taylor, éstas se produjeron en momentos clave, que facilitaron la extracción de las mismas, ya que muchos de los lienzos recogidos de los conventos exclaustrados de la ciudad se hallaban depositados en un salón de las Escuelas Pías y en el ex-convento de San Pablo, a los que Monroy tenía fácil acceso al ser el depositario de la llave del mismo. Así mismo, coincidieron con la invasión del general carlista Gómez, que gobernó y saqueó Córdoba desde el 30 de septiembre hasta el 13 de octubre de 1836, tiempo en el que se dio un clima de gran confusión, que sin duda, favoreció la rapiña de obras de arte ${ }^{51}$.

Los dos primeros recibos fueron expedidos en 19 de abril de $1836^{52}$, el primero de ellos alude a cinco pinturas de diferentes tamaños de las que no se indica la autoría, vendidas directamente al barón Taylor por el valor de 13.000 reales de vellón ${ }^{53}$. Ya hace tiempo que fueron identificadas algunas de ellas por Baticle y

49 A. N. P., $0^{4}$ 1275, Etat des dépenses relatives à la mission de M. Le Baron Taylor en Espagne pendant les années 1835, 1836 et 1837. Dépenser diverse, Carta dirgida a Luis Buisson, 23 diciembre de 1836.

50 A. N. P., $0^{4} 1725$, Acquisition de tableaux espagnols. Compte de $\mathrm{M}^{\text {r. Taylor. Etat des dépenses relatives à }}$ la mission de M. le Baron Taylor, en Espagne, pendant les années 1835, 1836 et 1837.

51 RAMÍREZ DE LAS CASAS-DEZA, L. M., Anales de la ciudad de Córdoba. Desde el Siglo XIII y año 1230 en que fue conquistada por el Santo rey don Fernando III, hasta el de 1850. Córdoba, Real Academia de Córdoba, 1948, págs. 278-304.

52 Gracias al Diario de Dauzats, sabemos que estuvo en Córdoba junto con el barón Taylor el 5 de abril de 1836, por lo que pudieron haber entrado en contacto con Diego Monroy para encargarle diversas compras, vid. GUINARD, P., Op. Cit., pág. 427.

53 Este primer recibo de 19 de abril de 1836 viene con su correspondiente traducción en francés, vid. A. N. P. $0^{4} 1275$ Etat des dépenses relatives à la mission de M. Le Baron Taylor en Espagne pendant les années 1835 , 
Marinas, tratándose pues de dos obras de Pedro Romana, que fueron atribuidas en esas fechas a Pedro de Córdoba ${ }^{54}$, tal y como lo muestra el primer catálogo de dicha galería, donde fueron citadas: "La Flagelación" 55 de la Gemälgalerie de Dresde y "La Muerte de San Jerónimo" ${ }^{6}$, siendo estas las únicas obras que se anotan en el citado catálogo como originales de Pedro Romana.

En ese sentido, discrepamos de las afirmaciones que mantiene José María Palencia ${ }^{57}$, según las cuales Monroy le vendió a Taylor el grupo entero del disperso retablo de la nave de la Epístola de la iglesia de San Nicolás de la Villa ${ }^{58}$, cuyas obras fueron repuestas con lienzos de la mano del propio Diego Monroy ${ }^{59}$. Una muestra evidente de lo que decimos, es que ninguna de las obras que supuestamente englobaron el citado retablo viene indicada en el "Catálogo de los cuadros de la Galería de Luis Felipe de Orleáns", algo que denota que no fueron vendidas al menos para formar parte de dicha colección, ya que el citado catálogo fue sumamente exhaustivo. Por lo tanto, a la luz de las pruebas documentales, lo que está claro es que Monroy en estas fechas vendió "La Flagelación" de Dresde y "La Muerte de San Jerónimo"60, que probablemente procedieron del convento de San Jerónimo de Valparaíso de Córdoba ${ }^{61}$. En cuanto a dos obras más de Pedro de Romana, que formaron parte del

1836 et 1837 . Achât de tableaux espagnole, 19 de abril de 1836:

"He recivido del Sr. Baron Tailor, la cantidad de trece mil reales vellon por cinco cuadros orijinales de diferentes autores pintados en lienzo y de distintos tamaños. Cordoba 19 de abril de 1836. Son 5 cuadros orijinales. Diego Monroy y Aguilera.

J'ai reçu de Monsieur le Baron Taylor la somme de treize mille réaux de vellon pour cinq tableaux originaux de differents auteur, penits sur toile et de differentes grandeurs. Cordoue 19 Avril 1836. Diego de Monroy et Aguilera".

54 BATICLE, J., y MARINAS, C., Op. Cit, págs. 72-73.

55 Según Antonio Urquízar Herrera, La Flagelación no es de la autoría de Pedro Romana. Además no correspondería al antiguo retablo de la iglesia de San Nicolás de la Villa como han indicado Jeannine Baticle y Cristina Marinas haciendo caso de las afirmaciones de Post. Vid. URQUÍZAR HERRERA, A., El Renacimiento en la periferia. La recepción de los modos italianos en la experiencia pictórica del Quinientos cordobés. Córdoba, Servicio de Publicaciones de la Universidad de Córdoba, 2001, pág. 41.

56 En dicho catálogo vienen documentados y numerados ambos cuadros como 78 y 79 respectivamente, vid. Notice des tableaux de la Galerie Espagnole exposés dans les salles du musée royal au Louvre. Paris, Imprimerie de Crapelet, 1838, pág. 25

57 PALENCIA CEREZO, J. M., Museo de Bellas Artes de Córdoba: Colecciones fundacionales (1835-1868). Córdoba, Museo de Bellas Artes de Córdoba, 1997, pág. 8.

58 El altar de Pedro Romana en la iglesia de San Nicolás de la Villa estaba formado por La Anunciación del Victoria and Albert Museum, La Virgen con el Niño de la Hispanic Society, y La Visitación de una colección particular, ninguna de estas obras se cita en el catálogo de la galería de Luis Felipe de Orleáns, vid. URQUÍZAR HERRERA, A., Op. Cit., pág. 41.

59 Sobre las sustituciones de las obras de Pedro Romana por las de Diego Monroy, vid. MADOZ, P. Diccionario geográfico-estadístico-histórico de España y sus posesiones de ultramar: Córdoba. Valladolid, Ámbito, 1987, pág. 125:

"...en el altar de la derecha se ven una Anunciación en un lado, la Visitación de Ntra. Sra. en otro, y en el último cuerpo la Virgen María con el niño Jesús, obras del citado D. Diego Monroy, que fueron puestas hace pocos años en lugar de otras que representaban iguales asuntos, al parecer del antiguo pintor cordobés (del siglo XV) Pedro de Córdoba..."

SEQUEIROS PUMAR, C., Estudio histórico-artístico de la iglesia de San Nicolás de la Villa de Córdoba. Córdoba, Publicaciones del Monte de Piedad y la Caja de Ahorros de Córdoba, 1987, págs. 124-125.

60 El paradero de esta obra es desconocido, BATICLE, J., y MARINAS, C., Op. Cit., pág. 73.

61 PALENCIA CEREZO, J. M., Op. Cit., pág. 9. 
catálogo de ventas efectuadas en Londres en 1853, poco se puede aportar, ya que se desconoce el paradero actual de las mismas, y ni siquiera se citó su iconografía en el catálogo de venta de $1853^{62}$. Sin embargo, conociendo la forma de actuar de Diego Monroy, bien pudo haberlas vendidas a otro comprador, ya que no sólo comerció con el barón Taylor, sino con otros muchos coleccionistas coetáneos ${ }^{63}$.

Pero además, con fecha 19 de abril de 1836, hay un segundo recibo en el que se le pagaron a Monroy 350 piastres fortes (aproximadamente unos 1.800 francos) que no ha citado la historiografía:

“J'attesté à M. Monroy, directeur de l'académie de Cordoue, deux tableaux pour la somme de 200 piastres fortes, et qu'il a payé 150 piastres trois autres tableaux qui lui ont été cédés par une dame de la ville. Cordoue le 19 Avril 1836. Alphonse de Rayneval64".

Aunque desconocemos a que obras se refiere este recibo, si nos evidencia como funcionó esta red de testaferros organizada por el barón Taylor. Así, su amigo e hijo del embajador francés en España, Alphonse de Rayneval notificó la entrega a Monroy de cierta cantidad de dinero a cambio cinco cuadros, dos obtenidos de la colección particular del propio Diego Monroy, y los tres restantes de una coleccionista cordobesa. Todo ello nos habla de cómo Monroy, conocedor del patrimonio pictórico cordobés, actuó como intermediario en la venta de dichos cuadros.

A finales de 1836, Córdoba se hallaba en un clima de gran inestabilidad, debido a las incursiones de los carlistas en Andalucía, que entraron en la ciudad el 30 de septiembre ${ }^{65}$. Todo esto generó un ambiente de profusos desórdenes, muy propicio para el robo de obras de arte. Pues bien, de estas fechas constan dos recibos más, uno de 19 de septiembre y otro de 4 de diciembre. En el primero se dio cuenta de 8.000 reales de vellón que recibió Monroy por varias pinturas, sin especificar ni la autoría ni la iconografía de ninguna de ellas $^{66}$. Mientras que el segundo ${ }^{67}$, sí entra más en detalle, y señala que recibió 2.000 reales de vellón por un cuadro de Antonio

62 BATICLE, J., y MARINAS, C., Op. Cit., págs. 267-269.

63 RAMíREZ DE ARELLANO Y GUTIÉRREZ, T., Paseos por Córdoba ó sean Apuntes para su Historia. Córdoba, Librería Luque, 1976, pág. 265-266.

64 A. N. P., $0^{4} 1275$, Etat des dépenses relatives à la mission de M. Le Baron Taylor en Espagne pendant les années 1835,1836 et 1837 . Achât de tableaux espagnole, 19 de abril de 1836.

65 BULLÓN DE MENDOZA, A., La expedición del General Gómez. Madrid, Editora Nacional, 1984.

66 El recibo viene con su correspondiente traducción en francés anexa, vid. A. N. P., $0^{4} 1275$ Etat des dépenses relatives à la mission de M. Le Baron Taylor en Espagne pendant les années 1835, 1836 et 1837. Achât de tableaux espagnole, 19 de septiembre de 1836:

"Recivi del Sr. Baron Taylor ocho mil reales de varias pinturas que le he proporcionado y para que conste lo firmo en Cordoba á 19 de septiembre de 1836

Diego Monroy y Aguilera.

J'ai reçu de monsieur Le Baron Taylor huit mille réaux de vellon pour plusieurs tableaux que je lui ai vendu et je le signe a Cordoue le 19 Septembre 1836.

Diego de Monroy y Aguilera".

67 Pocos días después de expedir este recibo, el día 8 de diciembre, Dauzats pasa por Córdoba, y seguramente se hizo cargo de dichas obras, vid. GUINARD, P., Op. Cit., pág. 428. 
del Castillo de su colección particular ${ }^{68}$. Según Baticle y Marinas, se trataría de un lienzo que representa a "San Juan Evangelista" y "San Juan Bautista" 69 , procedente de un altar localizado en la Iglesia franciscana del Monasterio de San Pedro el Real ${ }^{70}$, aunque en la actualidad se encuentre en la Gemälgalerie de Dresde ${ }^{71}$.

Los últimos recibos son de julio de 1837, cuando estaba finalizándose la renombrada misión. El primero, es de 14 de julio, en el que Monroy expresó que había recibido por cuenta de Dauzats y a través de José Paroldo ${ }^{72}$, la nada despreciable cantidad de 16.000 reales de vellón por "La Noche o Adoración de los Pastores" de José de Ribera:

"He recibido de estos Sres. Don José Paroldo é Hijos diez y seis mil reales de vellon por cuenta y orden Dn. Adriano Dausats. Córdoba 14 de Julio de 1837. Diego de Monroy y Aguilera.

J'ai reçu de M. Joseph Paroldo et son fils. Seize mille reaux au compte et par ordre de Mr. Adrien Dauzats. Cordoue 14 Juillet 1837. Signé. Diego de Monroy et Aguilera. (La nuit de Ribera) ${ }^{73 "}$.

Lo curioso, es que conocemos la iconografía de esta obra gracias a una anotación a lápiz realizada en el recibo traducido al francés, que no se indica en el original firmado por Diego Monroy. No obstante, y a pesar de la cuantía de la obra, seguramente no se trataba de un original de José de Ribera ${ }^{74}$.

El último de los recibos expedidos a nombre de Diego Monroy se fecha en 18 de julio. En el mismo recibió de manos de José Paroldo 36.000 reales de vellón por cuenta y orden de Dauzats, que se encontraba en esos momentos en Cádiz ${ }^{75}$.

68 A. N. P., $0^{4} 1275$ Etat des dépenses relatives à la mission de M. Le Baron Taylor en Espagne pendant les années 1835, 1836 et 1837. Achât de tableaux espagnole, 4 de diciembre de 1836:

"Recivi del sr. Baron Taylor dos mil reales de vellon por un cuadro mio de Castillo y para su resguardo lo firmo. Cordoba 4 de Diciembre de 1836. Diego de Monroy y Aguilera".

69 BATICLE, J., y MARINAS, C., Op. Cit., pág. 267-268.

70 Este original fue sustituido por una obra de Diego Monroy que reproducía el original de Antonio del Castillo, vid. CASTELLANO CUESTA, M. T., Las iglesias de San Francisco y San Eulogio de la Ajerquía de Córdoba. Córdoba, Publicaciones del Monte de Piedad y Caja de Ahorros de Córdoba, 1988, pág. 130; AA. VV., Guía artística de la provincia de Córdoba. Córdoba, Universidad de Córdoba, 1995, pág. 141.

71 PALENCIA CEREZO, J. M., Op. Cit., pág. 9.

72 José Paroldo, comerciante cordobés, ejerció de prestamista del barón Taylor para la compra de pinturas en Córdoba, vid. GUINARD, P., Op. Cit., pág. 221

73 Se trata del recibo original firmado por Diego Monroy, y su réplica traducida al francés, vid. A. N. P., $0^{4}$ 1275, Etat des dépenses relatives à la mission de M. Le Baron Taylor en Espagne pendant les années 1835, 1836 et 1837. Achât de tableaux espagnole. 14 de julio de 1837.

74 PALENCIA CEREZO, J. M., Op. Cit., pág. 8.

75 A. N. P., $0^{4} 1275$, Etat des dépenses relatives à la mission de M. Le Baron Taylor en Espagne pendant les années 1835, 1836 et 1837. Achât de tableaux espagnole. 18 de julio de 1837:

"He recibido de los Sres don José Paroldo é Hijos treinta y seis mil reales de vellon, por cuenta y orden de Don Adriano Dauzats de Cádiz. Córdoba 18 de Julio 1837.

Son 36000 r. Vellon. Diego Monroy y Aguilera.

J'ai reçu de M. Joseph Paroldo et son fils la somme de trente six mille reaux, pour compte et par ordre de Mr. 
Sin lugar a dudas, se trató de la cantidad de dinero más alta que cobró el pintor cordobés, y aunque no se especifica el concepto del recibo, estamos convencidos de que se trató de varias pinturas vendidas por Monroy a Dauzats, aunque precisar cuáles fueron concretamente, resulta a día de hoy una labor muy dificultosa, ya que no conocemos con exactitud ni la cantidad exacta y ni la autoría de las pinturas que pudo vender a tal precio.

Con todas estas ventas, Monroy ingresó unos 80.000 reales de vellón, cifra muy alta para la época y que lo situó a la cabeza de los que más dinero obtuvo por su trabajo en la misión del barón Taylor. Como hemos visto, esto fue consecuencia lógica del atropellado proceso de enajenación y venta de bienes de las órdenes religiosas, que propició que en un corto espacio temporal, se pusieran muchas de estas obras en manos de particulares. Estos nuevos coleccionistas no tuvieron ningún reparo en vender algunas de sus mejores obras al mejor postor.

En ese sentido, exponencialmente, a medida que se perdían gran parte de los lienzos que integraban las iglesias españolas a manos de marchantes europeos, el gusto por los pintores hispánicos se alzó hasta cotas impensables unos años antes.

Adrien Dauzats. Cordoue 18 juillet 1837. Diego de Monroy et Aguilera". 